\title{
CORRECTION
}

\section{Correction: UNC5B mediates G2/M phase arrest of bladder cancer cells by binding to CDC14A and P53}

Yexiang Huang, Yuyan Zhu, Zhe Zhang, Zhenhua Li and Chuize Kong (D)

(C) The Author(s), under exclusive licence to Springer Nature America, Inc. 2021

Cancer Gene Therapy (2022) 29:398; https://doi.org/10.1038/s41417-021-00394-6

Correction to: Cancer Gene Therapy https://doi.org/10.1038/ s41417-020-0175-x, published online 6 May 2020

We found an error in the published article UNC5B mediates G2/M phase arrest of bladder cancer cells by binding to CDC14A and P53. Cancer Gene Ther. 2020 Dec;27(12):934-947 (doi:10.1038/ s41417-020-0175-x) when we had a group discussion to review our previous research program. In detail, we misused a picture in the IHC experiment of CDC14A in Figure $6 \mathrm{D}$ (the first row and the second column), which represented the negative staining of
CDC14A in one of the related cells. We reviewed the submission process and found that the mistake occurred in the process of revising the original manuscript (as we did not carefully check the name of the negative-staining tumor tissue).

Nonetheless, this does not in any way impacts the scientific integrity or any conclusion we drew in the article.

The original article has been corrected. 